\title{
Porter Revisitado: Análise Crítica da Tipologia Estratégica do Mestre
}

\author{
Jorge Manoel Teixeira Carneiro \\ Maria Alice Ferreira Deschamps Cavalcanti \\ Jorge Ferreira da Silva
}

\section{RESUMO}

As estratégias genéricas de liderança em custo, diferenciação e enfoque desenvolvidas por Michael Porter (1980) vêm merecendo destacada aceitabilidade, tanto no meio acadêmico quanto no empresarial. Este artigo discute as opiniões de diversos autores de renome, os quais têm apresentado críticas, complementos e refinamentos a esta tipologia básica. Destaque especial é concedido a Chrisman, Hofer e Boulton (1988) e Miller e Dess (1993), por suas extensões à tipologia de Porter (1980), e a Mintzberg (1988), por seu trabalho de detalhamento da estratégia de diferenciação. Como contraponto à análise externa (baseada na estrutura da indústria) que orienta a tipologia de Porter (1980), são apresentados os conceitos da Resource-Based View, uma teoria de estratégias baseada nos recursos e competências da empresa (análise interna), ainda em desenvolvimento, mas que vem ganhando gradual aceitação no meio acadêmico. Por fim, a evolução do pensamento de Porter - de 1980 à 1996 - é analisada, de forma a evidenciar como o próprio autor vem detalhando e redefinindo o foco de seu objeto de estudo - da análise da estrutura da indústria até o sistema de atividades da empresa.

Palavras-chaves: estratégia, estratégia competitiva, estratégia de mercado, vantagem competitiva.

\begin{abstract}
Michael Porter's (1980) strategic typology is presented. Some critical analyses, complements and refinements advanced by many authors, especially Mintzberg (1988), are discussed. Some extensions proposed by Miller and Dess (1993) and Chrisman, Hofer and Boulton (1988) are also shown. The Resource-Based View is put forward as a counterpoint. The evolution of Porter's (1980) line of thought through the years - since 1980 until 1996 - is also discussed, which makes it possible to understand the way Porter (1980) has been detailing and redefining his focus - from industry structure up to the system of activities.
\end{abstract}

Key words: strategy, competitive strategy, market strategy, competitive advantage, resource-based view. 


\section{INTRODUÇÃO}

O conceito de estratégias (ditas) genéricas advém do fato de que alguns autores (e.g.: Miles et al., 1978; Porter, 1980, 1985; Hambrick, 1983a; Mintzberg, 1988) acreditam ser possível definir uma tipologia de estratégias suficientemente amplas de tal forma que elas sejam aplicáveis a qualquer empresa, em qualquer tipo de indústria e em qualquer estágio de desenvolvimento da indústria (Herbert e Deresky, 1987). Ou, dito de outra forma, poderia ser identificado um número limitado de arquétipos estratégicos que capturariam a essência das diversas posturas competitivas da maioria das empresas (Hambrick, 1983b).

Conforme Hambrick (1983a), a utilização de tipologias reduz o vasto leque de combinações que um pesquisador teria de considerar. Além disso, tipos (ou categorias) de uma tipologia representam caracteres gerais (gestalts), os quais definem um pacote holístico de atributos.

\section{Estratégias Genéricas de Porter}

Porter $(1980,1985)$ propôs uma tipologia composta por três estratégias genéricas (Figura 1): liderança no custo total; diferenciação e enfoque.

Segundo Porter (1980, 1985), as empresas que apresentariam melhor desempenho seriam aquelas que conseguissem aplicar uma, e apenas uma, das três estratégias genéricas. As empresas que procurassem uma estratégia híbrida ou que fracassassem na busca por uma das três estratégias foram por ele designadas como stuck-in-the-middle (expressão traduzida para o português como meio-ter$m o$ ). $\mathrm{O}$ fato de uma empresa ser classificada no meio-termo não significa que ela não emprega métodos e armas competitivas típicas de uma ou mais das estratégias genéricas, mas apenas que a sua estratégia como um todo carece de consistência interna (Dess e Davis, 1984). Porter $(1980,1985)$ sempre afirmou que uma empresa atuando no meio-termo apresentaria resultados inferiores aos daquelas que lograssem êxito no desenvolvimento de uma das três estratégias genéricas. Este posicionamento tem the valido diversas críticas (e.g.: Murray, 1988; Hill, 1988; Miller e Dess, 1993); o próprio Porter (1980, p.53; 1991, p.101) chegou a mencionar, numas poucas ocasiões e muito en passant, que seria viável a perseguição simultânea das estratégias de baixo custo e de diferenciação, dada uma determinada conjugação muito específica de circunstâncias. 
Figura 1: Estratégias Genéricas de Porter

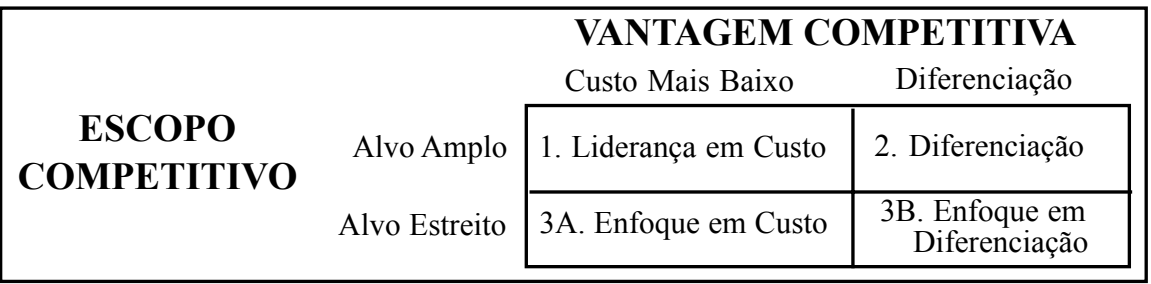

A extensa divulgação que a tipologia de Porter (1980, 1985) vem recebendo não apenas no meio acadêmico, mas também no meio empresarial e na imprensa especializada, tem tornado esta tipologia bastante conhecida; contudo apenas como forma de melhor situar o leitor para as seções que se seguirão, serão apresentadas as principais características dos três tipos estratégicos propostos por Porter (1980, 1985).

\section{Estratégia de Liderança no Custo Total}

O ponto central da estratégia de liderança no custo total é a empresa fazer com que seu custo total seja menor do que o de seus concorrentes. O custo mais baixo funciona como mecanismo de defesa da empresa contra a rivalidade de seus concorrentes, especialmente no tocante à guerra de preços.

Quando pressionada por fornecedores poderosos, a empresa de custo mais baixo terá mais fôlego para continuar na indústria do que seus concorrentes, que também estão sujeitos à pressão desses fornecedores. Raciocínio similar vale para a análise da empresa vis-à-vis das demais forças competitivas (ameaça de novos entrantes, ameaça de produtos substitutos e poder de negociação dos compradores).

Porter (1980, 1985) entende que somente pode existir um líder em custo numa indústria, porquanto, de contrário, a batalha por parcela de mercado entre várias empresas que aspiram à liderança em custo levaria a uma guerra de preços que seria desastrosa para a estrutura de longo prazo da indústria.

\section{Estratégia de Diferenciação}

A estratégia de diferenciação pressupõe que a empresa ofereça, no âmbito de toda a indústria, um produto ${ }^{(1)}$ que seja considerado único pelos clientes, ou seja, cujas características o distingam daqueles oferecidos pela concorrência. Hunt e Morgan (1995) comentam que a heterogeneidade dos gostos e necessidades dos clientes torna difícil falar-se em um mercado que atinja toda a indústria, quando, 
na realidade, existem segmentos de mercado. Contudo o conceito de um produto que atenda a toda a indústria assenta-se no fato de que podem existir características gerais que são valorizadas, em maior ou menor grau, pela maioria dos segmentos de mercado dentro da indústria.

A diferenciação oferece à empresa uma defesa contra as forças do ambiente, embora de forma diferente daquela permitida pela liderança em custo. A lealdade e a diminuição da sensibilidade ao preço (i.e., clientes dispostos a pagar mais para terem um produto que eles consideram que melhor atende às suas necessidades) isolam, em maior ou menor grau, a empresa da rivalidade de seus concorrentes. Similarmente, o poder dos compradores também diminui, uma vez que (por definição de produto diferenciado) eles não encontrarão no mercado outro produto com as mesmas características ${ }^{(2)}$. Argumentação similar pode ser aplicada na análise da vulnerabilidade da empresa em relação aos entrantes potenciais e produtos substitutos.

Considerando-se que a diferenciação pode permitir à empresa cobrar um preço prêmio, e desde que este preço prêmio cubra os eventuais custos adicionais em que a empresa incorre para diferenciar seu produto (e.g.: P\&D, qualidade dos insumos, melhor nível de serviço, propaganda, etc), a empresa possuirá uma margem maior que a de seus concorrentes, o que a tornará menos vulnerável do que estes em relação às pressões do ambiente.

Embora argumentando que não pode existir mais do que uma líder em custo, Porter $(1980,1985)$ afirma que pode haver várias empresas perseguindo e obtendo sucesso com uma estratégia de diferenciação, desde que cada uma delas se especialize em características ou atributos distintos dos das demais, e que haja um número suficiente grande de clientes que valorizem distintamente cada um destes atributos e características.

\section{Estratégia de Enfoque}

A estratégia de enfoque se baseia no fato de que a empresa será capaz de atender melhor ao seu alvo estratégico do que aqueles concorrentes que buscam atender a toda à indústria (ou a um grande número de segmentos da indústria). $\mathrm{O}$ alvo, ou escopo estratégico deve ser suficientemente estreito, de forma a permitir que a empresa o atenda mais eficientemente ou mais eficazmente, e pode ser definido sob diversas dimensões: tipo de clientes, linha de produtos, variedade do canal de distribuição, área geográfica. $\mathrm{O}$ alvo estreito pode ser atendido através de uma posição de custo mais baixo ou de uma posição de diferenciação, mesmo que a empresa não seja capaz de manter uma destas posições em relação à indústria como um todo. 


\section{Análise Crítica das Estratégias Genéricas de Porter}

\section{“Como" vs. "Onde"}

Uma das críticas mais comuns à taxinomia de estratégicas genéricas propostas por Porter $(1980,1985)$ é, na realidade, uma questão semântica: enquanto a liderança em custo e diferenciação se referem a como competir, enfoque se refere a onde competir (Mintzberg, 1988; Faulkner e Bowman, 1992).

\section{Críticas à Liderança em Custo}

Faulkner e Bowman (1992) citam que, na prática, tanto gerentes quanto pesquisadores, costumam, incorretamente, associar liderança em custo com concorrência em segmentos de preços baixos. Ser líder em custo também não significa, necessariamente, ser o fornecedor de menor preço (Partridge e Perren, 1994).

A propósito do fato de várias empresas buscarem ser líderes em custo, Porter $(1980,1985)$ afirma que a firma que alcançar esta posição deverá desencorajar as demais de também fazê-lo. Sharp (1991) sustenta uma posição contrária ao afirmar que, quando várias empresas buscam a liderança em custo (ou uma orientação para baixos custos), a estrutura da indústria se modifica, à medida que o mercado gradualmente se torna mais homogêneo (moldado pela oferta homogênea). Assim, o líder em custo seria beneficiado, pois haveria menos espaço para se buscar diferenciação.

Alguns autores também apresentam argumentos de que uma estratégia de custo baixo, acoplada com paridade em preço e nos atributos do produto, não constituiria vantagem competitiva sustentável, uma vez que o cliente não perceberia nenhuma diferença entre a oferta da empresa e outros produtos similares, cujos fabricantes apresentassem maiores custos de produção; como conseqüência, a empresa líder em custo não conseguiria obter a escala e a experiência suficientes para sustentar a sua vantagem de custos no longo prazo (Coyne, 1986; Faulkner e Bowman, 1992; Mintzberg, 1988). Esta afirmação é duvidosa, à medida que menores custos e paridade de preços e atributos resultariam em uma margem maior para o líder em custos; se não houver diferença nos demais fatores do ambiente competitivo, idêntica parcela com relação aos outros concorrentes, em suma lucros maiores. A questão está em determinar se o líder em custo poderia sustentar esta vantagem em caso de uma eventual mudança no ambiente competitivo. Sem dúvida, se ele tivesse sido capaz de traduzir seus menores custos em maior parcela de mercado (via preços mais baixos), ele poderia estar mais imune às forças do ambiente. 
Quanto à implementação da estratégia, existe uma dificuldade primária: conhecer os custos dos concorrentes. Além disso, a excessiva ênfase dada aos custos internos pode levar a empresa a sempre buscar soluções dentro da própria organização, ao invés de se relacionar adequadamente com os outros atores do ambiente competitivo [ver a propósito, Day e Wensley (1988), Day (1990), Zaccarelli e Fishmann (1994) para uma comparação entre estratégias voltadas para o cliente (foco externo) e estratégias voltadas para a concorrência (foco interno)].

\section{Críticas à Diferenciação}

Algumas críticas que Porter $(1980,1985)$ vem recebendo com relação à estratégia de diferenciação estão relacionadas ao fato de ele não distinguir se o retorno pela diferenciação advém de preço prêmio ou do aumento de parcela de mercado (a preços médios). Em verdade, esta crítica não procede, uma vez que fica a critério da empresa decidir como ela pretende traduzir sua vantagem em sucesso financeiro (Sharp, 1991).

Alguns autores entendem que a estratégia de diferenciação inclui um leque variado de estratégias competitivas distintas, as quais requerem estruturas e competências distintas para sua implementação e, portanto, este tipo estratégico merece ser desagregado numa classificação mais precisa.

Kim e Lim (1988), seguindo proposta básica de Miller (1987), subdividiram a estratégia de diferenciação, basicamente considerando-a como composta por: diferenciação no produto (atributos específicos, qualidade) e diferenciação por marketing (propaganda, nível de serviço).

Miller (1992) propôs três tipos de diferenciação: por qualidade, por inovação e por imagem. Em 1992 o mesmo autor realizou uma pesquisa entre empresas não diversificadas e encontrou três tipos de diferenciação: por qualidade (craftsmanship), por pioneirismo (pioneering) e por força de vendas (salesmanship).

Dentre os autores que têm criticado a insuficiência de detalhamento da estratégia de diferenciação de Porter (1980, 1985), destaca-se Mintzberg (1988), o qual será tratado numa seção específica adiante.

\section{Busca Simultânea de Diferenciaçăo e Liderança em Custo}

Na visão de Porter (1985, p.19-20), a busca simultânea das estratégias de liderança em custo e de diferenciação somente seria bem sucedida caso se observasse uma ou mais de algumas circunstâncias raras:

- quando todos os demais competidores estivessem competindo no meio-termo; 
- quando o custo fosse fortemente determinado pela parcela de mercado ou pelas interrelações entre indústrias que um concorrente pode explorar e outros não;

- quando a empresa fosse pioneira em uma inovação tecnológica importante e detivesse direitos exclusivos sobre ela.

Contudo Porter (1985) admite que estas circunstâncias são temporárias e que um competidor que logre sucesso na implementação de uma das estratégias "puras" ameaçará a posição daquele que procura sustentar sua vantagem por meio da implementação simultânea de ambas as estratégias. Porter (1996) sustenta que liderança em custo e diferenciação não são simultaneamente sustentáveis, mas se trai ao apresentar o exemplo da Southwest Airlines, empresa que reduziu seus custos ao cortar refeições, reserva de assentos e transferência de bagagem entre conexões (mas, como estes serviços acarretam atrasos às outras empresas aéreas, a Southwest acabou também se diferenciando em relação aos concorrentes).

Dess e Davis (1984), White (1986) e Miller e Dess (1993), confirmando os argumentos teóricos de Wright (1987), identificaram empresas bem sucedidas que se utilizavam simultaneamente das estratégias de diferenciação e de liderança em custo em um ou mais de seus segmentos alvo de produto-mercado, conforme também previsto por Hill (1988) e Karnani (1984).

Na opinião de Faulkner e Bowman (1992), assim como de Partridge e Perren (1994) e Sharp (1991), não há nenhum impedimento teórico em ser, ao mesmo tempo, diferenciado e líder em custo, desde que os atributos superiores do produto levem a um aumento de parcela de mercado, e esta a economias por escala e pela curva de experiência. Sharp (1991) acrescenta que todos os produtos devem possuir uma série de atributos básicos, sem os quais não poderão competir, e as empresas, mesmo em mercados de commodities, buscarão se diferenciar em intangíveis (serviço ou marca, por exemplo). Porter (1985), por seu lado, argumenta que a busca por ambas as estratégias geraria conflito organizacional e levaria a empresa a ficar no meio-termo.

Phillips, Chang e Buzzel (1983), citando Fine, argumentam que produtos de alta qualidade (ou seja, diferenciados) podem apresentar custos de produção mais baixos, pois a maior atenção e cuidados dos empregados na produção destes produtos, normalmente leva à descoberta e correção de falhas no sistema de produção, resultando numa redução nos custos (efeito da curva de experiência). Reforçando esta visão, Miller (1992) cita como exemplos os investimentos em controle de estoque just-in-time e na gestão pela qualidade total, os quais, além de melhorarem o serviço ao cliente e a qualidade dos produtos, também oferecem oportunidades para redução de custos.

Hill (1988) afirma que, sob certas circunstâncias, além de diferenciação e lide- 
rança em custo não serem antagônicas, a primeira ainda pode ser um meio de se alcançar a segunda. Tal situação dependeria do aumento da demanda proporcionada pela diferenciação e da diminuição dos custos unitários possibilitada pelo aumento do volume.

Segundo Hill (1988), o impacto da diferenciação sobre o aumento da demanda é modulado por três fatores (ou contingências) principais:

- capacidade da empresa em diferenciar o seu produto, que depende da existência de diversos atributos valiosos para os clientes e de diferentes possibilidades de uso do produto;

- natureza da competição (estágio de evolução da indústria e concentração relativa de fornecedores, compradores e concorrentes) - indústrias fragmentadas ou em crescimento oferecem maiores possibilidades de a diferenciação gerar aumento de parcela de mercado;

- comprometimento dos consumidores com os produtos dos concorrentes (altos custos de mudança dos clientes e significativa lealdade à marca dos concorrentes).

Quanto à extensão da redução de custos proporcionada pelo aumento de volume, as características da empresa, do produto, do processo de fabricação e da demanda devem ser tais que proporcionem significativas: (1) economias de escala; (2) economias de escopo (através do compartilhamento de recursos e de atividades) e (3) economias devidas ao aprendizado (dependentes da complexidade e da antigüidade do processo).

Dado um conjunto de circunstâncias (não necessariamente todas ao mesmo tempo) como as acima mencionadas, uma empresa pode, via diferenciação, vir também a alcançar uma posição de liderança em custo. Complementando sua análise, Hill (1988) cita, ainda, uma situação em que a liderança em custo pode preceder a diferenciação: quando a escala eficiente mínima é baixa (relativamente à demanda total), é possível que várias empresas alcancem uma posição de mínimo custo. Neste caso, aquela que conseguisse se diferenciar obteria vantagem competitiva sobre as demais, desde que, naturalmente, a diferenciação não implicasse aumento dos seus custos totais (o custo adicional imposto pela diferenciação propaganda, nível de serviço, etc - deveria ser compensado por economias de escopo) ou, alternativamente, a elasticidade da demanda ao preço fosse baixa o suficiente para tornar possível um preço prêmio.

\section{Abordagem Contingencial}

Alguns autores defendem uma visão que eles intitulam de contingencial, segun- 
do a qual o conjunto de estratégias viáveis é limitado pelas características do ambiente (Hambrick, 1983b; Murray, 1988). Segundo Varadarajan (1985), determinadas estratégias somente conduzirão a desempenho superior em função de configurações particulares do ambiente, da estrutura da indústria, do comportamento do consumidor, das estruturas organizacionais e da disponibilidade de recursos. Chrisman, Hofer e Boulton (1988) relacionam alguns exemplos de autores que desenvolveram tipologias de estratégias genéricas aplicáveis a circunstâncias específicas, tais como: situações de transição, indústrias em declínio, negócios de pequena participação de mercado, empresas de manufatura, integração vertical. Adicionalmente, Miller e Dess (1993) verificaram significativas divergências entre os retornos proporcionados pelas diferentes estratégias "genéricas" de Porter $(1980,1985)$, em oposição à premissa deste de que, numa dada indústria, os retornos seriam semelhantes para todas as empresas que implantassem com sucesso qualquer uma das estratégias genéricas.

Embora não explicitamente, o próprio Porter (1980) relaxou sua premissa de generabilidade ao estudar os diversos estágios de desenvolvimento de indústrias e tecer considerações amplas sobre quais estratégias seriam mais apropriadas para determinado estágio, que ele designa por "meio industrial genérico", classificado conforme o grau de concentração, competição global e estágio do ciclo de vida do produto, o que define cinco meios industriais: (1) indústrias fragmentadas, (2) emergentes, (3) em transição para a maturidade, (4) em declínio e (5) indústrias globais.

\section{Extensóes da Tipologia de Porter}

\section{Combinaçăo das Dimensões Estratégicas}

Miller e Dess (1993) propuseram uma nova tipologia segundo a qual os conceitos de custo, diferenciação e enfoque constituiriam dimensões de posicionamento estratégico. Ao invés de assumirem posições discretas, as empresas ocupariam posições num continuum ao longo das três dimensões.

Considerando, para simplificar a análise, que cada uma desta dimensões poderia assumir valores em três níveis (i.e., alto, médio e baixo), haveria então $3^{3}=27$ combinações possíveis. Contudo apenas algumas destas combinações seriam de interesse prático (por exemplo, a combinação de custo alto e baixa diferenciação obviamente não possui qualquer apelo). Em benefício da parcimônia, Miller e Dess (1993) limitaram seu modelo a sete combinações consideradas mais plausíveis (Figura 2): 
Figura 2: Uma Visão Tridimensional do Modelo de Porter com a Exibição dos Sete Tipos Estratégicos Propostos por Miller e Dess (1993)

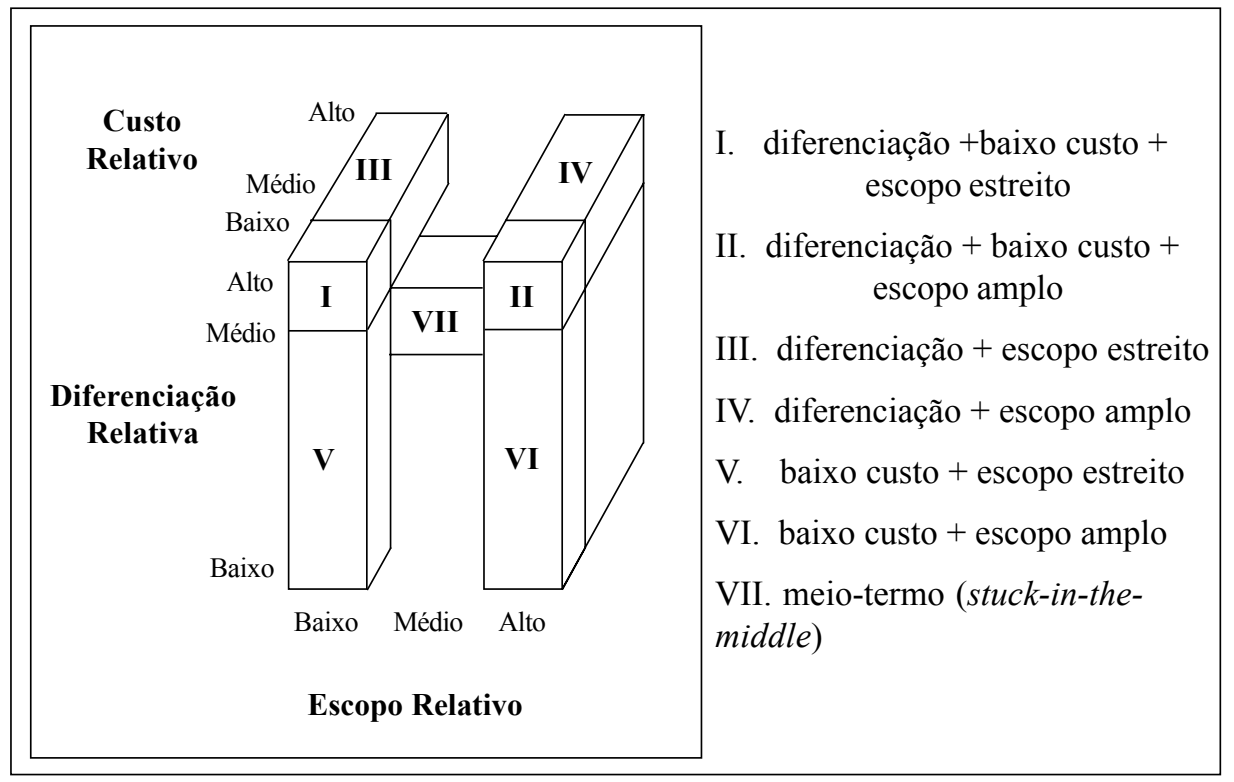

\section{Introdução de uma Dimensão Adicional}

Segundo Chrisman, Hofer e Boulton (1988), a tipologia de Porter $(1980,1985)$ não atenderia a duas características importantes de um sistema de classificação "científico"(3): homogeneidade interna e exaustividade. As razões básicas destas falhas seriam o fato de Porter $(1980,1985)$ não ter utilizado a "diversidade de vantagem competitiva por segmento" ${ }^{\text {(4) }}$ como dimensão relevante para a definição de sua tipologia de estratégias genéricas (falta de homogeneidade interna) e considerar mutuamente excludentes diferenciação e liderança em custo, assim como excluir a estratégia de meio-termo (falta de exaustividade). Em relação a este último aspecto, não consideramos a crítica válida, pois Porter (1980, 1985) descreve satisfatoriamente o tipo estratégico meio-termo.

Assim, com a tipologia de Porter $(1980,1985)$ não é possível fazer uma distinção entre estratégias de empresas que busquem vantagens competitivas ${ }^{(5)}$ distintas em diferentes segmentos de produto-mercado e as estratégias daquelas empresas que apresentam basicamente a mesma vantagem competitiva nos diversos segmentos de produto-mercado em que estão competindo. 


\section{Figura 3: Nova Tipologia de Estratégias Competitivas (Chrisman, Hofer e Boulton, 1988)}

\begin{tabular}{|c|c|c|c|}
\hline \multirow{2}{*}{$\begin{array}{l}\text { Diversidade de vantagem } \\
\text { competitiva por segmento }\end{array}$} & \multirow{2}{*}{$\begin{array}{l}\text { Tipo de vantagem } \\
\text { competitiva }\end{array}$} & \multicolumn{2}{|c|}{ Escopo } \\
\hline & & Amplo & Estreito \\
\hline \multirow{4}{*}{$\begin{array}{l}\text { Sim (diferentes tipos de } \\
\text { vantagens competitivas em } \\
\text { diferentes segmentos de } \\
\text { mercado) }\end{array}$} & Custo/Preço & $\begin{array}{l}\text { custo com } \\
\text { segmentação }\end{array}$ & $\begin{array}{l}\text { enfoque em custo } \\
\text { com segmentação }\end{array}$ \\
\hline & $\begin{array}{c}\text { Custo }+ \\
\text { Diferenciação }\end{array}$ & $\begin{array}{l}\text { utilidade com } \\
\text { segmentação }\end{array}$ & $\begin{array}{l}\text { enfoque em utilidade } \\
\text { com segmentação }\end{array}$ \\
\hline & Diferenciação & $\begin{array}{l}\text { diferenciação com } \\
\text { segmentação }\end{array}$ & \begin{tabular}{|c|} 
enfoque em \\
diferenciação com \\
segmentação \\
\end{tabular} \\
\hline & Nenhuma & falta de & $\begin{array}{c}\text { enfoque em fatta de } \\
\text { segmentação }\end{array}$ \\
\hline \multirow{4}{*}{$\begin{array}{l}\text { Não (mesmo tipo de } \\
\text { vantagem competitiva em } \\
\text { diferentes segmentos de } \\
\text { mercado) }\end{array}$} & Custo/Preço & $\begin{array}{c}\text { custo em mercado } \\
\text { de massa }\end{array}$ & enfoque em custo \\
\hline & $\begin{array}{c}\text { Custo }+ \\
\text { Diferenciação }\end{array}$ & $\begin{array}{c}\text { utilidade em } \\
\text { mercado de massa }\end{array}$ & $\begin{array}{l}\text { enfoque em } \\
\text { utilidade }\end{array}$ \\
\hline & Diferenciação & $\begin{array}{l}\text { diferenciação em } \\
\text { mercado de massa }\end{array}$ & $\begin{array}{c}\text { enfoque em } \\
\text { diferenciação }\end{array}$ \\
\hline & Nenhuma & $\begin{array}{l}\text { falta de vantagem em } \\
\text { mercado de massa }\end{array}$ & $\begin{array}{l}\text { falta de vantagem } \\
\text { em enfoque }\end{array}$ \\
\hline
\end{tabular}

(1) Utilidade foi usada para representar a obtenção simultânea, de forma equilibrada, das vantagens competitivas de custo e diferenciação no(s) principal(is) segmento(s) de produto/mercado em que a empresa atua.

(2) As categorias que aparecem cruzadas (falta de segmentação e enfoque em falta de segmentação) são teoricamente inconsistentes e devem ser excluídas da tipologia.

A nova tipologia, proposta por Chrisman, Hofer e Boulton (1988), apresentada na Figura 3, baseia-se em três níveis de classificação: escopo (amplo ou estreito), tipo de vantagem competitiva responsável pela maioria das receitas (4 tipos) e diversidade de vantagem competitiva por segmento ( $\operatorname{sim}$ ou não).

A estratégia de falta, apresentada na nova tipologia, estaria relacionada àquelas empresas que não se utilizam de nenhuma arma competitiva em particular, contentando-se, no máximo, em atender a um excesso de demanda. Estas empresas não possuem nenhum tipo de vantagem competitiva, com exceção, talvez, de se encontrarem no lugar certo no momento certo. 


\section{Detalhamento da Diferenciação: Estratégias Genéricas de MinTZBerG}

Mintzberg (1988) entende que a maioria das tipologias estratégicas explicitadas são falhas, seja por focarem de forma muito estreita em alguns tipos especiais de estratégias, seja por proporem agregações arbitrárias. Mintzberg (1988) propôs nova tipologia de estratégias genéricas, derivadas a partir do conceito de diferenciação e com nível de detalhamento maior que as estratégias de Porter (1980, 1985).

\section{Diferenciaçăo por Preço}

Uma forma de diferenciar um produto da oferta dos outros concorrentes pode ser, simplesmente, cobrar preço mais baixo. Se os demais atributos do produto forem iguais, ou não muito diferentes, dos de seus concorrentes, os consumidores tenderão a preferir aquele que exibir preço mais baixo. A empresa poderia obter lucros maiores que os seus concorrentes, se a queda na margem bruta fosse compensada pelo aumento do volume de vendas ou, complementarmente, se a empresa fosse capaz de desenvolver uma estrutura produtiva que lhe permitisse custo de produção mais baixo que o de seus concorrentes.

Mintzberg (1988) insiste em afirmar que diferenciação por preço não é o mesmo que minimização de custo (conforme Porter, 1980), porquanto esta última somente se caracterizaria como vantagem competitiva, caso se traduzisse em menor preço para o mercado, ou seja, caso fosse visível para o consumidor. A diferença é sutil e não facilmente defensável, porque custo mais baixo associado com paridade de preço levam a maior margem unitária e podem significar desempenho consistentemente superior ao dos concorrentes. Mintzberg (1988) concentra sua argumentação na premissa de que custo mais baixo está associado a menor nível de serviço ou a pior desempenho do produto, ignorando que diferentes tecnologias de produção e estruturas organizacionais apropriadas podem reduzir o custo total sem afetar outros atributos do produto.

Mintzberg (1988) admite que, em mercados de commodities, cujo preço é basicamente fixo, seria possível traduzir uma liderança em custo em vantagem competitiva sem ser necessário redução do preço. Implicitamente, Mintzberg (1988) se trai ao aceitar que, em algumas indústrias, é possível reduzir o custo sem necessariamente retirar outros atributos do produto.

De certa forma corroborando a posição de Mintzberg (1988), Cooper et al., citados por Chrisman, Hofer e Boulton (1988), assim como Sharp (1991), sugerem que diferenciação também pode ser obtida através da eliminação de "benefí- 
cios" que os clientes não valorizem, de tal forma a se poder obter um custo mais baixo e, assim, reduzir o preço (Sharp distingue explicitamente a vantagem de custo real - true cost advantage, advinda de eficiência de produção ou acesso privilegiado a recursos, da diferenciação ao contrário - “downward" differentiation, derivada de menor oferta de benefícios). Porter (1985), no entanto, entende que somente pode ser considerada como diferenciação aquela característica única de oferta que crie valor para o comprador, seja através da melhoria do seu desempenho ou da redução do seu custo (entenda-se que se trata de redução de custo não associada à redução de preço, mas à melhor integração do produto ofertado à cadeia produtiva ou ao processo de compra do cliente).

\section{Diferenciação por Imagem}

Uma vez que um dos atributos de um produto é a forma como os consumidores o percebem em comparação com os produtos concorrentes ou substitutos, uma empresa pode diferenciar seu produto ao desenvolver uma imagem que o torne distinto dos demais. Esta imagem pode ser criada através de propaganda, como também através de técnicas de promoção: apresentação e embalagem do produto, ou inclusão de detalhes que, embora não melhorando o desempenho do produto, $\mathrm{o}$ tornam mais atrativo para alguns clientes. Este tipo de diferenciação está muito relacionado com o conceito de sinalização de valor mencionado por Porter (1985), o qual enfatiza a importância dos detalhes quando os compradores não são capazes de discernir inteiramente as diferenças e as semelhanças entre produtos concorrentes.

Curiosamente, preço mais alto também pode ser utilizado como elemento realçador da imagem. O próprio Mintzberg (1988) cita o exemplo da vodka Smirnoff, que conseguiu aumentar sua parcela de mercado simplesmente a partir de um aumento de preço.

\section{Diferenciação por Suporte}

Uma forma de diferenciar o produto, sem necessariamente alterar seus atributos "intrínsecos", é oferecer algo mais junto com o produto, algo que Mintzberg (1988) também chama de diferenciação periférica. Este "algo mais" normalmente está relacionado com a ampliação do nível de serviços agregados (prazo de entrega menor, financiamento à venda, assistência técnica) ou com a oferta de produtos complementares. 


\section{Diferenciação por Qualidade}

Esta estratégia se caracteriza por oferecer (em nível de paridade de preço e custo ou a um custo mais alto compensado por preço de mercado também mais alto), um produto que, embora não fundamentalmente diferente, é melhor que os concorrentes. Basicamente o produto pode ser considerado melhor em três dimensões: (1) maior confiabilidade (i.e., menor probabilidade de falhas), (2) maior durabilidade ou (3) desempenho superior.

Ao contrário da diferenciação por imagem, que Mintzberg (1988) entende como derivada de investimentos em propaganda e promoção, a diferenciação por qualidade advém dos atributos do próprio produto em si.

\section{Diferenciação por Design (projeto)}

Uma forma de diferenciar um produto é oferecê-lo ao mercado com características distintas dos produtos concorrentes. Trata-se, na verdade, de oferecer um produto diferente, em substituição aos da concorrência.

A diferença básica desta estratégia para aquela de diferenciação por qualidade é que a diferenciação por design busca efetivamente oferecer algo "diferente" e não simplesmente ou necessariamente "melhor". Trata-se de um conceito similar ao da diferenciação por inovação conforme proposto por Miller $(1987,1988)$.

\section{Não-diferenciação}

Trata-se de uma estratégia muito observada na prática, a qual se baseia no fato de que é possível copiar as ações de outras empresas, desde que o mercado ofereça espaço para produtos concorrentes e a empresa se especialize em acompanhar e imitar os lançamentos dos concorrentes e apoiar seus próprios lançamentos com ações inovadoras e eficientes de marketing.

A estratégia de não-diferenciação assemelha-se ao conceito de meio-termo desenvolvido por Porter (1980). Duas diferenças, no entanto, merecem destaque:

a) Mintzberg (1988) considera que a estratégia de não-diferenciação pode ser desenvolvida explicitamente, enquanto Porter (1980) considera o meio-termo como um tipo residual, resultante da implementação inadequada ou ineficiente de uma das estratégias genéricas "puras";

b) Ao contrário do que Porter (1980) supõe para o meio-termo, Mintzberg (1988) não "condena" a estratégia de não-diferenciação a um desempenho inferior ao das demais estratégias. 
Em um estudo com empresas de manufatura nos Estados Unidos, Kotha e Vadlamani (1995) concluíram que a tipologia de Mintzberg (1988) exibe maior clareza e poder descritivo que a tipologia de Porter (1980). Em resposta a outros estudos que confirmaram o poder descritivo da tipologia de Porter (e.g.: Dess e Davis, 1984), Kotha e Vadlamanin (1995) levantam as seguintes possíveis explicações para justificar os novos resultados: (1) mudanças no ambiente competitivo devido ao incremento da competição global (especialmente no setor de manufatura) e (2) mudanças decorrentes da utilização de novas tecnologias (por exemplo, just in time). A maior complexidade do novo ambiente competitivo exigiria maior refinamento das tipologias de estratégias genéricas.

\section{Críticas da Resource-Based View}

Durante a década de 1980, o principal foco da análise estratégica foi a ligação entre o ambiente externo (a estrutura da indústria), a estratégia e o conseqüente desempenho das empresas, sendo praticamente desprezada a relação entre os recursos e competências da empresa e sua escolha estratégica. Sem dúvida, o trabalho de Porter $(1980,1985)$ constitui-se no principal exemplo daquela perspectiva.

Contudo, a partir do final da década, surgem vários estudos empíricos (Schmalensee, 1985; Cubbin e Geroski (apud Hill e Deeds, 1996); Hansen e Wernerfelt, 1989; Rumelt, 1991) que mostram que a influência das características das empresas sobre suas rentabilidades relativas é muito mais significativa do que a influência da indústria à qual as empresas pertencem.

Estes autores estudaram as características necessárias dos recursos para que estes se tornassem uma fonte de vantagem competitiva sustentável, a influência das barreiras de imitação sobre as diferenças de rentabilidade entre as empresas, o papel da história da empresa na obtenção e desenvolvimento de competências organizacionais críticas (a estratégia futura da empresa como condicionada pelas suas escolhas no passado), a importância das diferenças das rotinas organizacionais para explicar as diferenças de rentabilidade entre as empresas, etc. Em conjunto, estas contribuições são denominadas como a Resouce-Based View, e constituem contraponto ou complemento à análise estratégica de Porter $(1980,1985)$.

Para Foss (1996) a Resouce-Based View da empresa é uma real alternativa teórica ao modelo de Porter $(1980,1985)$ de análise da estrutura da indústria (modelo das cinco forças) para a definição das estratégias da empresa, pois ambas as teorias enfocam essencialmente o mesmo fenômeno (as possibilidades para as empresas obterem retornos acima da média), utilizando, contudo, instrumentais explicativos muito diferentes. 
Contudo outros autores (Barney, 1991; Mahoney e Padian, 1992; Foss, 1996 no final de seu artigo) observam uma clara complementaridade da Resource-Based View com o modelo de Porter $(1980,1985)$ de análise da indústria, pois este permite a identificação das ameaças e oportunidades externas, enquanto a ResourceBased View pode fornecer uma análise mais consistente das forças e fraquezas da empresa, pois introduz um entendimento superior das condições para a empresa obter uma vantagem competitiva sustentável.

Dentro do enfoque da Resource-Based View, a origem básica da rentabilidade da empresa são alguns recursos valiosos, escassos, sem substitutos e de difícil imitação (Barney, 1991). Nesta visão, a estratégia competitiva é a arte de criação, acumulação e utilização destes recursos, ao invés da construção de barreiras de entrada em face dos demais concorrentes nos segmentos-alvos de produto/mercado (Foss, 1996).

Juttner e Wehrli (1994), Prahalad e Hamel (1990) e Grant (1991) fazem clara distinção entre recursos e competências. Os recursos seriam elementos básicos, não específicos, que podem ser adquiridos ou imitados em certo grau, tais como equipamentos, recursos financeiros, tecnologia, marca, habilidade de empregados individuais, etc. Por outro lado, as competências seriam elementos de nível superior, específicos da empresa, resultantes do aprendizado organizacional e da combinação única de vários recursos. Prahalad e Hamel (1990) utilizam o termo core competencies (competências essenciais) e consideram que estas são o aprendizado coletivo da organização, especialmente de como coordenar diversos recursos e tecnologias.

De modo geral, a Resource-Based View sugere que a formulação da estratégia seja iniciada pela identificação dos recursos e competências existentes na empresa, seguida pela avaliação da sustentabilidade da vantagem competitiva que eles podem proporcionar, para então escolher a estratégia que melhor utilize esses recursos e competências para explorar as oportunidades e/ou neutralizar as ameaças do seu ambiente externo.

A principal questão da crítica da Resource-Based View à análise estratégica, baseada na perspectiva de Porter $(1980,1985)$, não é quanto ao grau de influência da estrutura da indústria sobre a lucratividade da empresa, mas quanto às limitações que a postura de atenção, centrada na estrutura da indústria, freqüentemente cria quanto à capacidade da empresa de inventar novos produtos, de ingressar rapidamente em mercados emergentes (aproveitar as oportunidades externas em qualquer lugar que ocorram) ou de alterar as escolhas dos clientes nos mercados maduros.

Prahalad e Hamel (1990) consideram que apenas no curto prazo a vantagem 
competitiva de uma empresa deriva dos atributos de preço e desempenho de seus produtos, pois no longo prazo esta seria decorrente da capacidade de desenvolver internamente, ao menor custo e mais rapidamente que os concorrentes, as competências que permitem a criação de muitos produtos novos (não previstos pelas condições atuais de demanda). Ou em outras palavras, no mundo atual mais incerto e dinâmico (as preferências dos clientes são voláteis e as tecnologias estão em contínua evolução), a vantagem competitiva da empresa reside naquelas competências que permitem o acesso da empresa a uma grande variedade de mercados (existentes ou que possam ser criados).

\section{Evoluçāo do Pensamento de Porter}

Em seu primeiro livro - Competitive Strategy, Porter (1980) explica o sucesso das empresas em função da atratividade da indústria (avaliada pelo seu modelo das cinco forças) e do posicionamento relativo da empresa dentro desta indústria, o qual é apenas conseqüência de uma vantagem competitiva (representada pela implementação de uma das estratégias genéricas anteriormente apresentadas).

Nesta primeira abordagem é marcante a ênfase da análise estratégica a partir do ambiente externo; várias vezes, Porter (1980) afirma que a estrutura da indústria é o fator preponderante na escolha da estratégia da empresa. Conseqüentemente, a estratégia competitiva é vista como a construção de defesas contra o conjunto das forças competitivas, como um modo de influenciar o equilíbrio das forças externas em favor da empresa, ou como uma resposta, antes dos concorrentes, às mudanças no fatores básicos destas forças (Porter, 1980, p.45). Portanto, neste estágio, a pergunta básica que Porter (1980) se propõe responder é "Por que as indústrias diferem quanto ao seu potencial de lucro?".

Já no seu segundo livro - Competitive Advantage, Porter (1985) procura identificar as fontes (drivers) de vantagem competitiva da empresa, utilizando o modelo da cadeia de valor ${ }^{(6)}$ como forma de análise sistemática de todas as atividades executadas por uma empresa, assim como o modo como elas estão ligadas entre si ou às atividades de outras empresas (fornecedores, canais de distribuição, consumidores finais, etc). Ou seja, Porter (1985) procura descrever o modo como uma empresa pode obter uma vantagem de custo sustentável ou diferenciar-se de seus concorrentes. Entretanto, segundo Foss (1996), não há discussão elaborada de como os recursos e competências suportam as atividades.

A partir desta abordagem, a estratégia competitiva é definida como a criação de uma posição única e valiosa, a partir da configuração de um conjunto diferente de 
atividades (quanto ao seu conteúdo singular ou modo de execução distinto). Porter (1985) pretende, assim, responder "Por que empresas de uma mesma indústria apresentam diferenças de rentabilidade sustentáveis a longo prazo?".

Foss (1996) destaca que, ao longo de seu trabalho, Porter (1985) apresenta modificações com relação aos conceitos básicos de empresa e de origem da vantagem competitiva. Em relação ao conceito de empresa, Porter $(1980,1985,1990)$ considera esta, ora como uma função de produção (quando é analisada a estrutura da indústria), ora como um conjunto de atividades interrelacionadas (quando tenta identificar as fontes da vantagem competitiva), ora como depósito de conhecimento produtivo e entidade geradora de inovações (quando elabora seu modelo de "diamante" para explicar a competitividade das nações).

Quanto à vantagem competitiva, Foss (1996) observa que, inicialmente, Porter (1980) considera-a apenas como resultante da criação de barreiras de entrada ou de mobilidade. Entretanto, em 1985, Porter apresenta a vantagem competitiva como decorrente da coordenação superior das atividades da empresa, enfatizando assim a eficiência em relação aos concorrentes e as barreiras de imitação das suas fontes (drivers de custo ou de diferenciação) como forma de mantê-la sustentável.

Esta segunda visão é reforçada em 1996, quando Porter afirma que a vantagem competitiva sustentável provém do modo como as atividades se ajustam entre si e se reforçam mutuamente, fazendo com que a configuração de uma atividade aumente o valor competitivo de outras atividades.

Neste estágio, Porter (1996) apresenta uma visão sistêmica da vantagem competitiva, pois conclui que a vantagem competitiva de uma empresa está no sistema complexo de suas atividades, nas suas relações (ajuste), e não nas partes (forças específicas, competências essenciais ou recursos críticos da empresa. Em recente seminário Porter (1997) reforçou este aspecto ao afirmar: "O todo importa mais do que qualquer parte individual'.

Conseqüentemente, Porter (1996) afirma que um posicionamento construído sobre um sistema de atividades possui maior sustentação do que aquele baseado em atividades isoladas, pois é bastante difícil para observadores externos compreender os elos relevantes deste sistema ou para os concorrentes reproduzi-los integralmente.

Neste aspecto Porter (1996) parece aproximar-se da Resource-Based View, pois esta perspectiva alternativa considera que a vantagem competitiva deriva de competências essenciais, que são basicamente a integração de vários recursos (semelhante ao sistema de atividades anteriormente citado), e que estas só serão fonte de uma vantagem competitiva sustentável, se não for possível para as outras empresas copiá-las. 
Além disso, Porter (1991) considera que as alternativas para o posicionamento da empresa e conseqüentemente de configuração de sua cadeia de valor são em parte limitadas pelas condições iniciais da empresa, ou seja, por seus recursos existentes. Embora esta restrição seja dinâmica, pois decisões gerenciais podem levar à criação de novos recursos, necessários para a estratégia escolhida, Porter (1991), em certo grau, parece aceitar uma das premissas da Resource-Based View, ou seja, da influência da história da empresa sobre suas estratégias.

Mas mesmo após valorizar o papel dos recursos da empresa, Porter (1991) retorna à sua posição inicial de ênfase no ambiente, pois observa que suas pesquisas sobre os determinantes da Vantagem Competitiva das Nações (Porter, 1990) mostraram que a origem da vantagem competitiva reside mais nas características do ambiente do que nas condições iniciais da empresa.

Em seu trabalho mais recente Porter (1996) apresenta três possíveis bases, não mutuamente excludentes, para o posicionamento competitivo de uma empresa que, segundo ele, devem ser consideradas como um nível adicional de detalhamento das suas estratégias genéricas básicas (liderança em custo, diferenciação e enfoque), ou seja:

- variedade (produção de apenas alguns tipos produtos da indústria, que satisfazem um subconjunto das necessidades dos clientes);

- necessidade (atendimento de quase todas as necessidades de um grupo específico de consumidores ou de uma ocasião de compras distintas);

- acessibilidade (atendimento de clientes com necessidades similares, mas acessíveis de maneiras diferentes).

\section{Conclusão}

As análises críticas ao modelo de Porter $(1980,1985)$ servem bem para ilustrar o quanto outros pesquisadores vêm procurando aperfeiçoar e rever as idéias básicas do autor. O próprio Porter vem modificando e ampliando sua tipologia mas sem aceitar explicitamente as contribuições de outras linhas de pesquisa. Ele considera, por exemplo, que a Resource-Based View apresenta uma visão apenas parcial da análise estratégica, não sendo suficiente para explicar o sucesso e o fracasso das empresas.

A Resource-Based View, apesar de se apresentar como promissor contraponto e complemento às fontes de vantagem competitiva desenvolvidas por Porter, ainda não se firmou como base teórica nem encontrou seu espaço nas pesquisas empíricas, 
pois falta ainda operacionalizar os seus conceitos básicos, como por exemplo: barreiras de imitação, competências essenciais e dependência histórica (dentre mais de cem artigos sobre estratégias competitivas consultadas pelos autores deste artigo, apenas Collis (1991) utilizou empiricamente a Resource-Based View como ferramenta explicativa, contudo realizando uma análise somente qualitativa).

Algumas tipologias que se apresentam como concorrentes à de Porter (e.g.: Mintzberg, 1988; Chrisman, Hofer e Boulton, 1988; Miller e Dess, 1993) infelizmente ainda não receberam validação empírica suficiente para que se possa julgar adequadamente a sua aplicabilidade como alternativa à sua tipologia.

A revisão do modelo de Porter $(1980,1985)$ aqui conduzida, permite não só entender melhor as próprias idéias do autor, como também é útil como forma de contextualizar e relativizar a sua validade e aplicabilidade.

\section{NOTAS}

${ }^{1}$ A rigor, a palavra "produto" deveria ser substituída pela expressão "produto ou serviço". No entanto, para tornar a leitura mais fácil, em todo o texto será utilizada apenas a palavra "produto", mesmo quando a situação permita uma inferência também para o ramo de serviços.

${ }^{2}$ É importante ressaltar que o produto, conforme visto pelo cliente, engloba não apenas as características físicas e de desempenho, mas também as dimensões intangíveis (ex: prazo de entrega, assistência técnica, financiamento às vendas, atendimento personalizado, marca). A diferenciação se pode situar nas características do produto como nas dimensões intangíveis (serviços agregados, imagem, etc).

${ }^{3} \mathrm{O}$ termo "cientifico" foi utilizado por Chrisman, Hofer e Boulton (1988).

${ }^{4} \mathrm{O}$ conceito de "diversidade de vantagem competitiva por segmento" significa a obtenção (ou não) de vantagens competitivas diferentes em cada segmento de mercado.

${ }^{5}$ Chrisman, Hofer e Boulton (1988) utilizaram o termo "arma competitiva" para designar a ênfase da empresa em custo, diferenciação ou combinação destes. Contudo, para manter coerência com a terminologia adotada por Porter $(1980,1985)$ neste artigo será utilizada a expressão "vantagem competitiva".

${ }^{6} \mathrm{O}$ modelo da cadeia de valor permite a divisão da empresa nas suas atividades de relevância estratégica para a compreensão dos custos e das fontes existentes ou potenciais de diferenciação (Porter, 1985). 
ReFERÊnCIAS BibLIOGRÁfICAS

BARNEY, J. B.

Firm resources and sustained competitive advantage. Journal of Management, v.17, n.1, p.99120, 1991.

CHRISMAN, J. J.;

HOFER, C. W.;

BOULTON, W. R.

Toward a system for classifying business strategies. Journal Academy of Management Review, v.13, n.3, p.413-428, 1988.

COLLIS, D. J.

A resource-based analysis of global competition : the case of the bearings industry. Strategic Management Journal, v. 12, p.49-68, 1991.

COYNE, K. P.

Sustainable competitive advantage : what it is, what it isn't. Business Horizons, v.29, n.1, p.54-61, 1986.

DAY, G. S.

Estratégia voltada para o mercado : processos para criação de valor dirigidos ao cliente. Rio de Janeiro : Record, 1990.

DAY, G. S.;

WENSLEY, R.

Assessing advantage : a framework for diagnosing competitive superiority. Journal of Marketing, v.52, p.1-20, Apr. 1988.
DESS, G. G.;

DAVIS, P. S.

Porter's (1980) : generic strategies as determinants of strategic group membership and organizational performance. Academy of Management Journal, v.27, n.3, p.467-488, Sept. 1984.

FAULKNER, D.;

BOWMAN, C.

Generic strategies and congruent organisational structures : some suggestions. European Management Journal, v.10, n.4, p.494-499, Dec. 1992.

FOSS, N. J.

Research in strategy, economics and Michael Porter. Journal of Management Studies, v.33, n.1, p.1-24, Jan. 1996.

GRANT, R. M.

The resourced-based theory of competitive advantage : implications for strategy formulations. California Management Review, p.114135, Spring 1991.

HAMBRICK, D. C.

An empirical typology of mature in-dustrial-product environments. Academy of Management Journal, v.26, n.2, p.213-230, 1983a.

High profit strategies in mature capital goods industries : a contingency approach. Academy of Management Journal, v.26, n.4, p.687-707, 1983 b. 
HANSEN, G. S.;

WERNERFELT, B.

Determinants of firm performance : the relative importance of economic and organizational factors. Strategic Management Journal, v.10, n.5, p.399-411, 1989.

HERBERT, T. T.;

DERESKY, H.

Generic strategies : an empirical investigation of typology and strategy content. Strategic Management Journal, v.8, p.135-147, 1987.

HILL, C. W. L.

Differentiation versus low cost or differentiation and low cost : a contingency framework. Academy of Management Review, v.13, n.3, p.401-412, July 1988.

HILL, C. W. L.;

DEEDS, D. L.

The importance of industry structure for the determination of the firm profitability : a neoaustrian perspective. Journal of Management Studies, v.33, n.4, p.429-451, July 1996.

HUNT, S. D.;

MORGAN, R. M.

The comparative advantage theory of competition. Journal of Marketing, v.59, p.1-15, Apr. 1995.

JUTTNER, U.;

WEHRLI, H. P.

Competitive advantage : merging marketing and the competencebased perspective. Journal of Business \& Industrial Marketing, v.9, n.4, p.42-53, 1994.
KARNANI, A.

Generic competitive strategies : an analytical approach. Strategic Management Journal, v.5, p.367-380, 1984.

KIM, L.;

LIM, Y.

Environment, generic strategies and performance in a rapidly changing country : a taxonomic approach. Academy of Management Journal, v. 31 , p.802-827, 1988.

KOTHA, S.;

VADLAMANI, B. L.

Assessing generic strategies : an empirical investigation of two competing typologies in discrete manufacturing industries. Strategic Management Journal, v.16, p.75-83, 1995.

MAHONEY, J. T.;

PANDIAN, J. R.

The resource-based view within the conversation of strategic management. Strategic Management Journal, v. 13, p.363-380, 1992.

MILES, R. E. et al.

Organizational strategy, structure, and process. Academy of Management Review, v.3, n.3, p.546-562, July 1978.

MILLER, A.;

DESS, G. G.

Assessing Porter's (1980) : model in terms of its generability, accuracy and simplicity. Journal of Management Studies, v.30, n.4, p.553-585, July 1993.

MILLER, D.

The structural and environmental correlates of business strategy. Strategic Management Journal, v.8, p.55-76, 1987. 
Relating Porter's business strategies to environment and structure : analysis and performance implications. Academy of Management Journal, v.31, n.2, p.280-308, 1988.

The Icarus paradox : how exceptional companies bring about their own downfall. New York : Harper Collins, 1990.

Generic strategies : classification, combination and context. In: SHRIVASTAVA, P. (Ed.). Advances in strategic management. Greenwich, Conn.: Jay Press, 1992. v.8. p.391-408.

MINTZBERG, H.

Generic strategies : toward a comprehensive framework. In: SHRIVASTAVA, P. (Ed.). Advances in strategic management. Greenwich, Conn.: Jay Press, 1988. v.5. p.1-67.

MURRAY, A. I.

A contingency view of Porter's : generic strategies. Academy of Management Review, v.13, n.3, p.390-400, July 1988.

PARTRIDGE, M.;

PERREN, L.

Developing strategic direction : can generic strategies help? Management AccountingLondon, v.72, n.5, p.28-29, May 1994.

PHILIPS, L. W.;

CHANG, D. R.;

BUZZEL, R. D.

Product quality, cost position and business performance : a test of some key hypotheses. Journal of Marketing, v.47, p.26-43, Spring 1983.
PORTER, M. E.

Competitive strategy : techniques for analysing industries and competitors. New York : Free Press, 1980.

Competitive advantage : creating and sustaining competitive performance. New York : Free Press, 1985.

The competitive advantage of nations. Harvard Business Review, p.73-93, Mar./Apr. 1990.

Towards a dynamic theory of strategy. Strategic Management Journal, v.12, p.95-117, 1991.

What is strategy? Harvard Business Review, p.61-78, Nov./ Dec. 1996.

PRAHALAD, C. K.;

HAMEL, G.

The core competence of the corporation. Harvard Business Review, p.79-91, May/June 1990.

RUMELT, R. P.

How much does industry matter? Strategic Management Journal, v.12, p.167-85, 1991.

SCHMALENSEE, R.

Do markets differ much? American Economic Review, v.75, n.3, p.341-350, 1985.

SHARP, B.

Competitive marketing strategy : Porter revisited. Marketing Intelligence \& Planning, v.9, n.1, p.04-10, 1991.

VARADARAJAN, P. R.

A two-factor classification of competitive strategy variables. Strategic Management Journal, v.6, p.357-375, 1985. 
WHITE, R. E.

Generic business strategies, organizational context and performance : an empirical investigation. Strategic Management Journal, v.7, p.217231, 1986.

WRIGHT, P.

A refinement of Porter's strategies. Strategic Management Journal, v.8, p.93101, 1987.

ZACCARELLI, S. B.;

FISCHMANN, A. A.

Estratégias genéricas : classificação e usos. Revista de Administração de Empresas, v.34, n.4, p.13-22, jul./ago. 1994. 